\title{
StABILITY OF RETAined Austenite in High-STRENGTH MARTENSITIC SteEls DURING COLd DEFORMATION
}

\author{
Štěpán Jeníček, Dagmar Bublíková, Hana Jirková, Josef Káňa
}
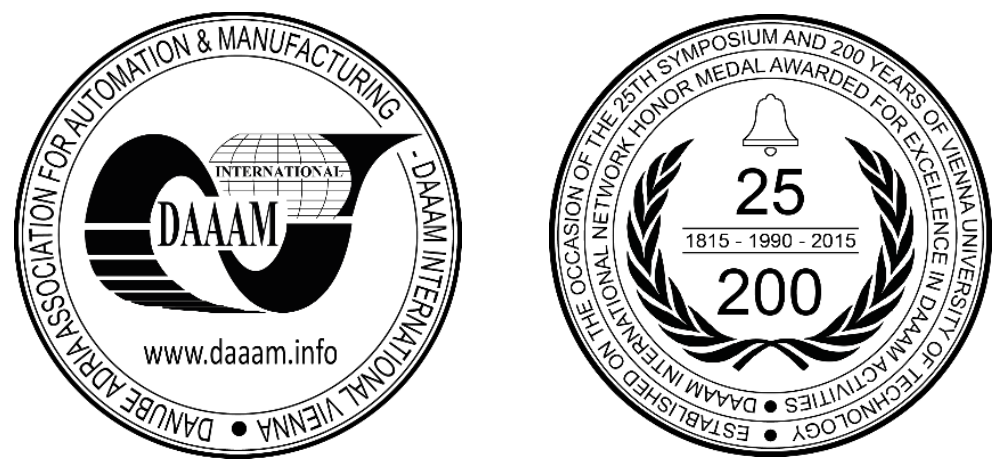

This Publication has to be referred as: Jenicek, S[tepan]; Bublikova, D[agmar]; Jirkova, H[ana] \& Kana, J[osef] (2017). Stability of Retained Austenite in High-Strength Martensitic Steels during Cold Deformation, Proceedings of the 28th DAAAM International Symposium, pp.0289-0294, B. Katalinic (Ed.), Published by DAAAM International, ISBN 9783-902734-11-2, ISSN 1726-9679, Vienna, Austria DOI: $10.2507 / 28$ th.daaam.proceedings.039

\begin{abstract}
The toughness of high-strength steels is improved when their martensitic matrix is combined with the presence of retained austenite. The stability of retained austenite is crucial, both upon cooling to room temperature and during subsequent cold deformation. One of the advanced heat treatment methods, which produces larger amounts of retained austenite in martensitic matrix thanks to an appropriate combination of parameters, is the Q\&P process (Quenching and Partitioning). It produces microstructures consisting of martensite and retained austenite which exhibit strengths above $2000 \mathrm{MPa}$ and elongation levels of more than $10 \%$. The steel which was designed for this experiment was alloyed with manganese, silicon, molybdenum and chromium and had a low Ms temperature.

This experimental heat treatment led to a martensitic microstructure with retained austenite, with ultimate strengths in the range of 2200-2400 MPa and $\mathrm{A}_{5 \mathrm{~mm}}$ elongations of 7-10\%. The largest fraction of retained austenite, according to X-ray diffraction analysis, was $10 \%$. The behaviour of retained austenite under mechanical load was studied by means of compression tests to various strain levels. The resulting microstructures were observed using optical and scanning electron microscopes..
\end{abstract}

Keywords: Q-P process; AHSS steels; retained austenite; X-ray diffraction

\section{Introduction}

Retained austenite in the final microstructure of advanced steels is an important phase which provides a combination of strength and ductility. An advanced processing technique for achieving the same combination is the Q\&P (Quenching and Partitioning) process by which strengths in the vicinity of $2000 \mathrm{MPa}$ and elongation levels of approximately $10 \%$ can be obtained [1], [2], [3]. Q\&P processing relies on cooling from the fully austenitic region to a region between the $\mathrm{M}_{\mathrm{s}}$ and $\mathrm{M}_{\mathrm{f}}$, whereby the martensite transformation is arrested, and subsequent reheating to a partitioning temperature. The stock is held at this temperature while retained austenite becomes stabilized by carbon which diffuses from the super-saturated martensite [4], [5]. For the purpose of application of high-strength steels, both chemical and mechanical stability of retained austenite must be known, as it is the behaviour of retained austenite during cold deformation which substantially dictates final mechanical properties. As the growing use of such steels also expands their potential for components operating at elevated temperatures, the stability of retained austenite under various thermal loading temperatures becomes 
relevant. The main factors determining whether retained austenite remains stable in martensitic matrix include its morphology, particle size and distribution. Its chemical stability also depends on alloying. Therefore, once appropriate heat treatment parameters are confirmed to provide a sufficient proportion of retained austenite, the behaviour of retained austenite under cold deformation must be ascertained as well.

\section{Experimental programme}

Since the Q\&P process is characterized by interrupting the quench at a specific temperature between the $\mathrm{M}_{\mathrm{s}}$ and $\mathrm{M}_{\mathrm{f}}$, its industrial use is technically demanding. For this reason, the proposed experimental steel had a manganese level of $2.45 \%$ (Table 1), which considerably depressed the $\mathrm{M}_{\mathrm{s}}$ to $209^{\circ} \mathrm{C}$ and the $\mathrm{M}_{\mathrm{f}}$ to $78^{\circ} \mathrm{C}$. A very low $\mathrm{M}_{\mathrm{f}}$ temperature is expected to simplify the entire heat treatment process. Manganese improves mechanical properties of steel through its effect on solid solution strengthening and retained austenite stabilization. The stability of retained austenite is also controlled by silicon which also prevents carbides from forming, and therefore provides sufficient super-saturation of martensite with carbon. The carbon content was $0.4 \%$. Nickel was used for improving austenite stability and for better hardenability. Transformation temperatures were calculated by means of the JMatPro software [10].

\begin{tabular}{|c|c|c|c|c|c|c|c|c|c|c|c|c|}
\hline $\mathrm{C}$ & $\mathrm{Mn}$ & $\mathrm{Si}$ & $\mathrm{P}$ & $\mathrm{S}$ & $\mathrm{Cu}$ & $\mathrm{Cr}$ & $\mathrm{Ni}$ & $\mathrm{Al}$ & $\mathrm{Mo}$ & $\mathrm{Nb}$ & $\mathrm{M}_{\mathrm{s}}$ & $\mathrm{M}_{\mathrm{f}}$ \\
\hline 0.419 & 2.45 & 2.09 & 0.005 & 0.002 & 0.06 & 1.34 & 0.56 & 0.005 & 0.04 & 0.03 & 209 & 78 \\
\hline
\end{tabular}

Table 1. Chemical composition of experimental steel with reduced $\mathrm{M}_{\mathrm{s}}$ temperature [wt \%]

\subsection{Q\&P Process}

Several different Q\&P sequences were carried out on the experimental steel (Tab. 2). Their parameters were defined on the basis of earlier experiments [4]. Quenching temperature was chosen with reference to earlier experiments and a calculation using the Magee-Koistinen-Marburger formula (Eq. 1), [11], [12]. This equation yields an estimate of the martensite fraction dictated by the chosen quenching temperature (Fig. 1).

$$
f_{i}^{a}=1-\exp [-1.10 \times 10-2(\mathrm{Ms}-\mathrm{Tq})
$$

where $f_{i}^{a}$ is the volume fraction of martensite, $T_{q}$ is the quenching temperature (QT) and $M_{s}$ corresponds to the $\mathrm{M}_{\mathrm{s}}$ temperature calculated using JMatPro. This calculation shows that at a quenching temperature of $150^{\circ} \mathrm{C}$, the material retains $53 \%$ of austenite. While the stock is held at the partitioning temperature (PT), a certain amount of retained austenite becomes stabilized by carbon which migrates from super-saturated martensite, whereas the remaining portion of retained austenite decomposes into martensite as the stock is cooled to room temperature.

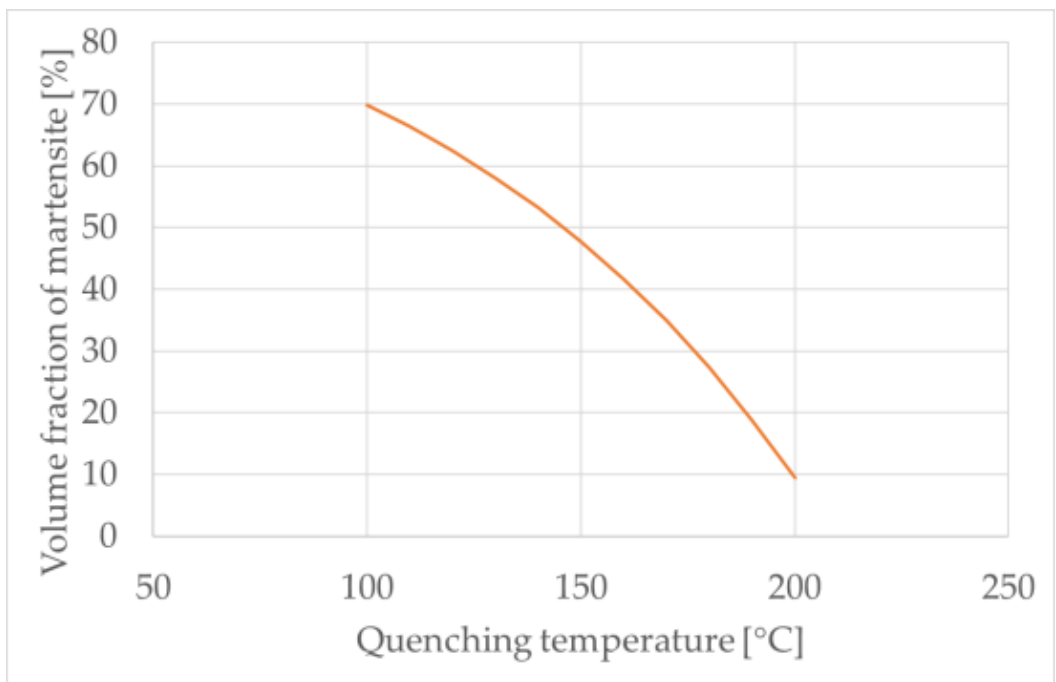

Fig. 1. Martensite volume fraction vs. quenching temperature (QT) 
The Q\&P process comprised heating to an austenitizing temperature (TA) of $850^{\circ} \mathrm{C}$, soaking for 100 or 300 seconds (sequences 1, 2 and sequence 3) and quenching to QT at $16^{\circ} \mathrm{C} / \mathrm{s}$ (sequence 1) or $1^{\circ} \mathrm{C} / \mathrm{s}$ (sequences 2 and 3). The QT was $150^{\circ} \mathrm{C}$ in all sequences. This was followed by reheating to a partitioning temperature of $200^{\circ} \mathrm{C}$, holding for $600 \mathrm{~s}$ and cooling to room temperature.

Since specific process parameters need to be used to obtain the desired mechanical properties, the heat treatment sequence was carried out in a thermomechanical simulator [6], [7], [8].

\subsection{Stability of retained austenite during cold deformation}

The stability of retained austenite and its transformation to strain-induced martensite during cold deformation is of key importance, which is why the behaviour of retained austenite under load needs to be characterized. Based on earlier results, sequence 2 was selected which had produced $12 \%$ retained austenite (RA) (Table 2). Specimens processed according to this sequence were compressed in the thermomechanical simulator to $\varphi=0.13$ at room temperature and at various strain rates $\left(10^{-3}, 10^{-1}, 10 \mathrm{~s}^{-1}\right)$. After this deformation, the retained austenite volume fraction was measured by $\mathrm{X}$ ray diffraction again and compared with the value before deformation (Table 3).

\begin{tabular}{|c|c|c|c|c|c|c|c|c|}
\hline Sequence No. & $\mathbf{T}_{\mathbf{A}}\left[{ }^{\circ} \mathbf{C}\right] / \mathbf{t}_{\mathbf{A}}[\mathbf{s}]$ & $\begin{array}{c}\text { Cooling } \\
\text { rate }\left[{ }^{\circ} \mathbf{C} / \mathbf{s}\right]\end{array}$ & $\begin{array}{c}\mathbf{Q T} \\
{\left[{ }^{\circ} \mathbf{C}\right]}\end{array}$ & $\begin{array}{c}\mathbf{P T}\left[{ }^{\circ} \mathbf{C} / \mathbf{s}\right] \\
/ \mathbf{t} \mathbf{P T}[\mathbf{s}]\end{array}$ & $\begin{array}{c}\mathbf{H V 1 0} \\
{[-]}\end{array}$ & $\begin{array}{c}\mathbf{R}_{\mathbf{m}} \text { (UTS) } \\
{[\mathbf{M P a}]}\end{array}$ & $\begin{array}{c}\mathbf{A}_{\mathbf{5 m m}} \\
{[\mathbf{\%}]}\end{array}$ & $\begin{array}{c}\mathbf{R A} \\
{[\%]}\end{array}$ \\
\hline 1 & $850 / 100$ & 16 & 150 & $200 / 600$ & 716 & 2200 & 5 & - \\
\hline 2 & $850 / 100$ & 1 & 150 & $200 / 600$ & 679 & 2308 & 10 & 12 \\
\hline 3 & $850 / 300$ & 1 & 150 & $200 / 600$ & 708 & 2367 & 9 & 9 \\
\hline
\end{tabular}

Table 2. Q\&P sequences and results of mechanical tests

\begin{tabular}{|c|c|c|}
\hline Strain rate $\left[\mathrm{s}^{-1}\right]$ & HV10 [-] & RA [\%] \\
\hline $10^{-3}$ & 452 & 6 \\
\hline $10^{-1}$ & 460 & 4 \\
\hline 10 & 482 & 3 \\
\hline
\end{tabular}

Table 3. Retained austenite volume fraction in relation to strain magnitude

The microstructures obtained by processing were examined using an optical microscope (Olympus XXX) and a scanning electron microscope (Tescan Vega 3).

Mechanical properties were determined via HV10 hardness and by means of tensile testing on miniature specimens with a gauge length of $5 \mathrm{~mm}$.

The amount of retained austenite was measured by means of XRD phase analysis in the automatic powder diffractometer AXS Bruker D8 Discover with a position-sensitive area HI-STAR detector and a cobalt X-ray source $(\lambda \mathrm{K} \alpha=0.1790307$ $\mathrm{nm})$.

\section{Discussion of results}

Three Q\&P sequences were carried out on the experimental steel with a reduced martensite transformation temperature. They involved various soaking times and cooling rates of 16 and $1{ }^{\circ} \mathrm{C} / \mathrm{s}$.

The first sequence, in which the austenitizing temperature was $850^{\circ} \mathrm{C}$, the soaking time was $100 \mathrm{~s}$ and cooling took place at $16^{\circ} \mathrm{C} / \mathrm{s}$, ending at the quenching temperature of $150^{\circ} \mathrm{C}$, produced a martensitic-bainitic microstructure with a hardness of $716 \mathrm{HV} 10$ (Fig. 2). The ultimate strength reached $2200 \mathrm{MPa}$ and elongation was $\mathrm{A}_{5 \mathrm{~mm}}=5 \%$. High hardness and low elongation were due to high cooling rate. Slowing down the cooling rate from $16^{\circ} \mathrm{C} / \mathrm{s}$ to $1{ }^{\circ} \mathrm{C} / \mathrm{s}$ in sequence 2 has led to a larger bainite fraction and higher elongation: $10 \%$ (Fig. 3). Appreciable carbide precipitation and a small amount of ferrite were found by metallographic observation. Nevertheless, the volume fraction of retained austenite was high, reaching $12 \%$. Extending the time at the austenitizing temperature from $100 \mathrm{~s}$ to $300 \mathrm{~s}$ in sequence 3 was not reflected in any way in microstructural evolution or mechanical properties (Table 2).

As the largest final fraction of retained austenite of $12 \%$ was found upon sequence 2 , which involved a quenching temperature of $150^{\circ} \mathrm{C}$ and a cooling rate of $1^{\circ} \mathrm{C} / \mathrm{s}$, the specimens obtained with this sequence were selected for testing the stability of retained austenite upon after cold deformation. 
Q\&P-processed specimens were subjected to compressive deformation of $\varphi=0.13$ applied at various rates: $10^{-3}, 10^{-1}$, $10 \mathrm{~s}^{-1}$. The resulting microstructure was a mixture of martensite and bainite with small amounts of pearlite and retained austenite and exhibited no appreciable effects of deformation. The highest retained austenite $6 \%$ austenite was preserved at the lowest strain rate (Table 3). Influence to the high strain rate, the residual austenite was transformed into martensite, which corresponded to the higher hardness of 482 HV10 (Table 3).

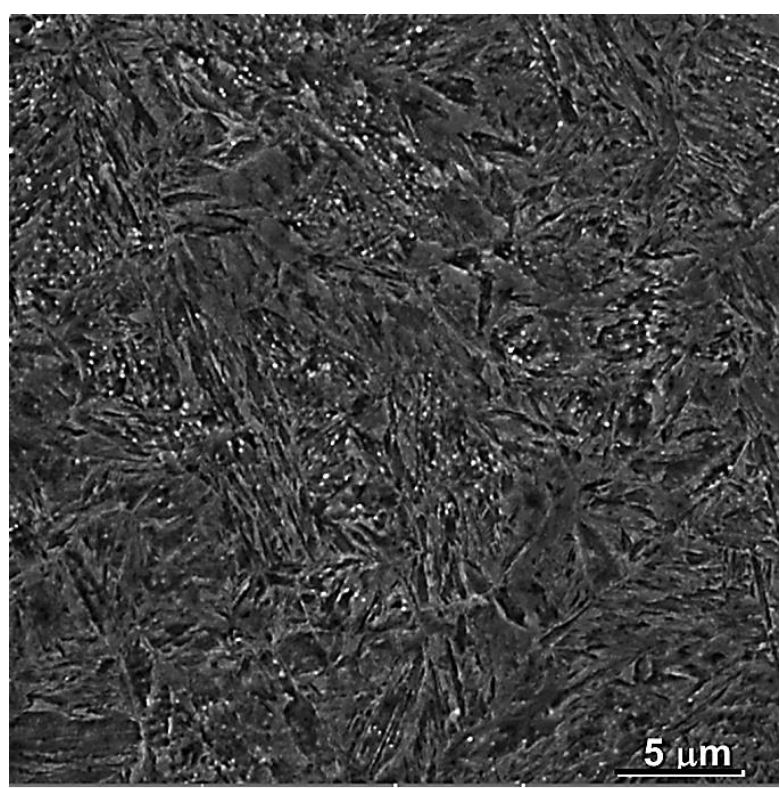

Fig 2. Sequence 1 - Martensitic microstructure with a smaller amount of bainite and retained austenite scanning electron micrograph

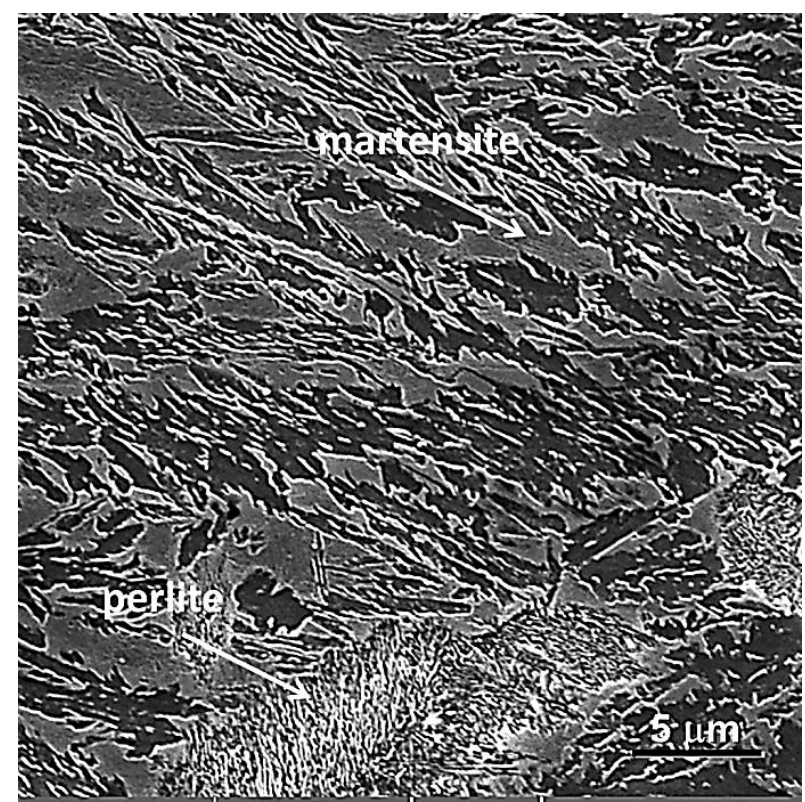

Fig 4. Sequence 2 - Post-compression condition, strain rate of $10^{-3} \mathrm{~s}^{-1}$ - martensitic-bainitic microstructure with a small volume fraction of pearlite and retained austenite scanning electron micrograph

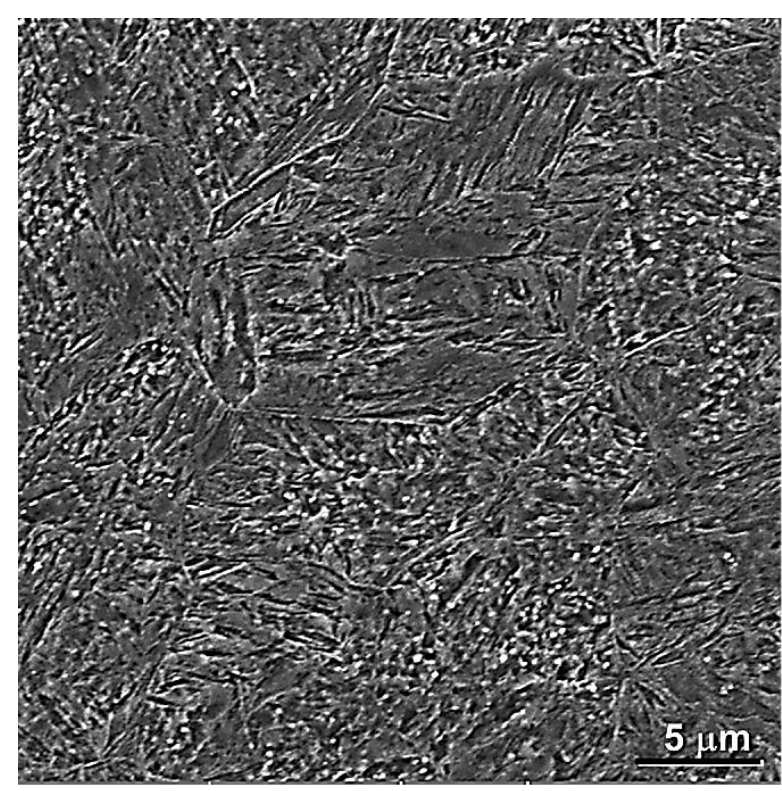

Fig 3. Sequence 2 - Martensitic microstructure with a larger amount of bainite and $12 \%$ of retained austenite scanning electron micrograph

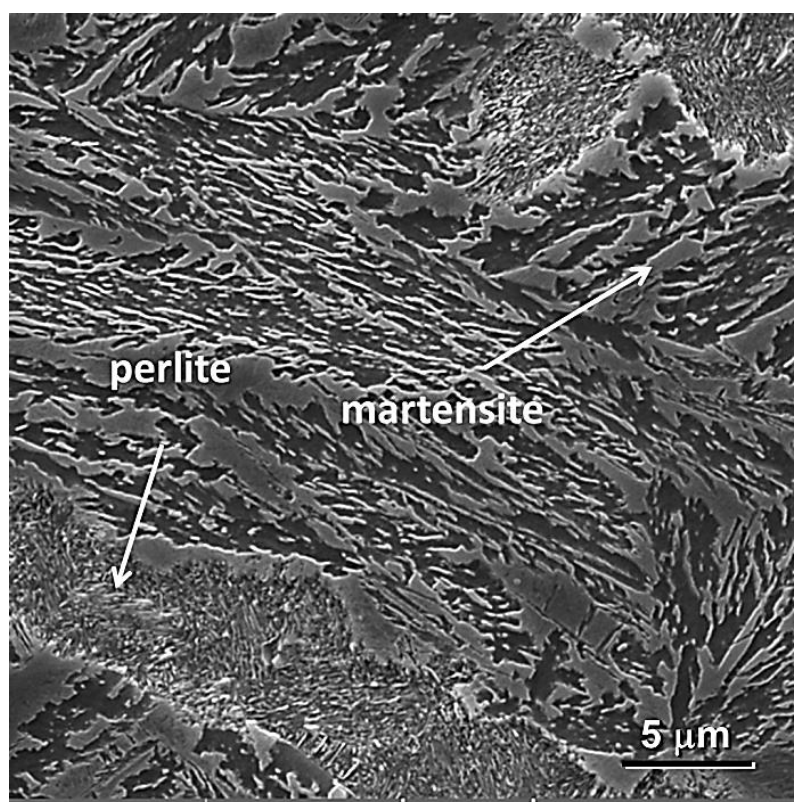

Fig. 5. Sequence 2 - Post-compression condition, strain rate of $10^{-1} \mathrm{~s}^{-1}$ - martensitic-bainitic microstructure with a small volume fraction of pearlite and retained austenite scanning electron micrograph 


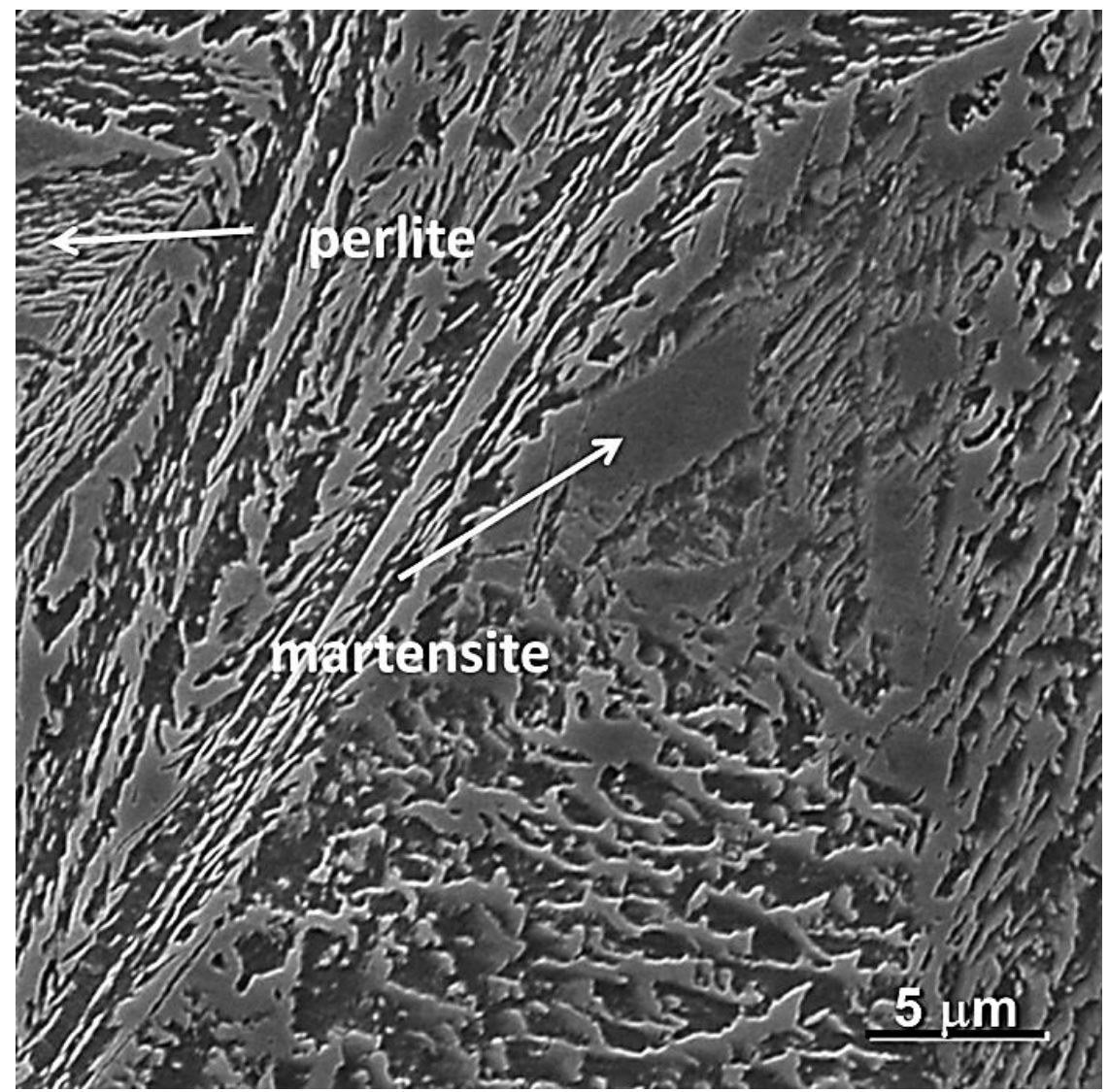

Fig 6. Sequence 2 - strain rate of $10^{-1} \mathrm{~s}-1$ - martensitic-bainitic microstructure with a small volume fraction of pearlite and retained austenite - scanning electron micrograph

\section{Conclusion}

An experimental AHS-type steel with a reduced $\mathrm{M}_{\mathrm{s}}$ temperature and a carbon content of $0.4 \%$ and a manganese level of $2.5 \%$ was experimentally treated using the $\mathrm{Q} \& \mathrm{P}$ process with various times at the austenitizing temperature and various rates of cooling to the quenching temperature. Slowing down the cooling rate from $16^{\circ} \mathrm{C} / \mathrm{s}$ to $1{ }^{\circ} \mathrm{C} / \mathrm{s}$ changed the character of the microstructure. A larger volume fraction of bainite was obtained, together with a small amount of pearlite. Despite that, XRD phase analysis revealed $12 \%$ of retained austenite in the material. The ultimate strength exceeded $2000 \mathrm{MPa}$ and the elongation level was $10 \%$.

Specimens processed in this manner were then compressed at room temperature and at various strain rates. Influence to the pressure deformation, retained austenite was transformed into martensite. The highest retained austenite rate was preserved at the lowest deformation rate of $6 \%$.

\section{Acknowledgments}

This paper includes results achieved within the project SGS-2016-060 Research of Modern AHS Steels and Innovative Processing for their Manufacturing. The project is subsidised from specific resources of the state budget for research and development.

\section{References}

[1] Mašek, B.; Jirková, H.; Hauserová, D.; L. Kučerová, Klaubeová, D. (2010). TheEffect of Mn and Si on the Properties of Advanced High Strength Steels Processed by Quenching and Partitioning, Materials Science Forum, Vol. 654656, pp. 94-97

[2] Jirková, H.; Kučerová, L.; B. Mašek, B. (2012). Effect of Quenching and Partitioning Temperatures in the Q-P Process on the Properties of AHSS with Various Amounts of Manganese and Silicon, Materials Science Forum, Vol. 706-709, pp. 2734-2739 
[3] Edmondsa, D.V.; Hea, K.; Rizzo, F.C.; De Coomanc, B.C.; Matlock, D.K.; Speer, J.G. (2006). Quenching and partitioning martensite - A novel steel heat treatment, Materials Science and Engineering A, Vol. 438-440, pp. 2534

[4] Ibrahim, K.; Bublíková, D.; Jirková, H.; Mašek, B. (2015) Stabilization of Retained Austenite in High-Strength Martensitic Steels with Reduced Ms Temperature, In METAL 2015. Ostrava: TANGER spol. s r. o., pp. 1-7. ISBN: 978-80-87294-58-1

[5] Qian, Z.; Lihe, Q.; Jun, T.; Jiangying, M.; Fucheng, Z. (2013) Inconsistent effects of mechanical stability of retained austenite on ductility and toughness of transformation-induced plasticity steels, Materials Science \& Engineering A, Vol. 578, pp. 370-376,

[6] Jirková, H.; et al. (2014) Influence of metastable retained austenite on macro and micromechanical properties of steel processed by the Q-P proces, Journal of Alloys and Compounds, Vol. 615, pp. S163-S168

[7] Brushi, S.; Altan, T.; Banabic, D. (2014) Testing and modelling of material behaviour and formability in sheet metal forming, Cirp Annals In: Manufacturing Technology, Vol. 63, pp. 727-749,

[8] Mašek, B.; Jirková, H.; Malina, J.; Skálová, L.; Meyer, W. (2007) Physical Modelling of Microstructure Development During Technological Processes with Intensive Incremental Deformation In Key Engineering Materials, Vol. 345-346, pp. 934-946,

[9] J. Káňa, J.; I. Vorel, I.; Ronešová, A. (2015) Simulator of Thermomechanical Treatment of Metals, In Daaam 2015. Vienna: Daaam International Vienna, pp. 0513-05018, ISBN: 978-3-902734-07-5, ISSN: 1726-9679

[10] JMatPro, Release 9.0, Sente Software Ltd., 2016.

[11] Zhu, Y. et al. (2012) Stepping-quenching-partitioning treatment of 20SiMn2MoVA steel and effects of carbon and carbide forming elements. Sci China Tech Sci 2012, 55, 1838-1843

[12] Koistinen, D.P. (1959) Marburger, R.E. A general equation prescribing the extent of the austenite-martensite transformation in pure iron-carbon alloys and lain carbon steels. Acta Metallurgica, vol. 7, pp. 59-60. 